\title{
Discussion of Session IV
}

\author{
Chairman: Professor J. G. Scadding
}

Q: May I ask about the dose of chlorambucil?

Professor H. L. IsRael: For chlorambucil we use $2 \mathrm{mg}$ q.i.d. on a long-term basis; methotrexate in the same dosage schedule as has been generally used for psoriasis. We have given $20 \mathrm{mg}$ by mouth twice a week.

DR P. BALDRY (Ashford Hospital, Middlesex): Is there a place for prednisone in the treatment of pulmonary infiltration without symptoms in order to prevent ultimate fibrosis?

ISRAEL: I think the great difficulty is that it is almost impossible to run a controlled trial of long-term steroid therapy, and obviously the controlled trial we did carry out had to be a short one, and for that reason perhaps inconclusive, you could argue that a longer trial would have done more to alter the eventual outcome. I think myself, however, from the combination of this brief trial and from the clinical experience that, in fact, steroids really do not alter the eventual outcome unless they do it in cases of Stage I alone. So far as cases with pulmonary infiltration are concerned, I will henceforth I think treat only for symptomatic relief.

Dr F. Kellerman (St Mary's Hospital, Colchester): Both Professor Scadding and Professor Israel emphasized the importance of spontaneous regressions in sarcoidosis. In my experience, amongst my patients of child-bearing age, these regressions are more or less the rule. I would very much like to hear Professor Scadding's views whether this is a general experience and, if so, whether this has been looked upon as a possibility of a hormonal approach to the treatment of sarcoidosis?

Professor J. G. Scadding: I think it is true to say that most people have found that in older patients, of middle age and over, the proportion getting complete spontaneous regression is smaller than in younger patients. I think this applies to both sexes so I do not think it is particularly related to child-bearing and that sort of thing. Perhaps Professor Israel might have some observations on that?

ISRAEL: Nothing to add to that.

Q: Can I ask about the effect of chlorambucil on the blood count? One uses it in the leukaemias in the dose mentioned. When $20 \mathrm{mg}$ chlorambucil is used does not he get any depression of bone marrow on that dosage? How frequently do you do the blood counts?

ISRAEL: I should have made that warning that we have taken blood counts both with chlorambucil and methotrexate every 2 weeks. We have had to suspend treatment briefly in a few patients because the count fell below 3000 . I think what has impressed us greatly is that in patients with this far advanced pulmonary disease, as a rule a disease that supposedly impairs immunologic defences and then adding immunosuppressive drugs, so called, we really did not encounter any complications, no intercurrent infections of consequence at all. So I suspect that much of the trouble you get into treating your leukaemics is because they have leukaemia.

Q: How long do you go on?

ISRAEL: Well, many of the patients were treated for 6 months. We have one or two we have kept on it longer.

DR J. B. Dilawari (Bedford General Hospital): Have AFB been discovered in cases of sarcoidosis after treatment with steroids for a long time?

ISRAEL: For a good many years we did not give isoniazid with our steroids, which in a sense was a deliberate challenge, and I think the Scandinavians did the same, and in neither country did anyone encounter any cases of frank tuberculosis occurring, and in recent years we followed the policy of giving isoniazid to everyone who is a reactor to intermediate strength tuberculin, and we do it whether or not they get steroids. We are doing it simply because we think everyone should have a year of isoniazid prophylaxis.

SCADDING: It now falls to my lot to bring this symposium to an end. I am sure that you will all wish me to express to Dr Mikhail and his colleagues at the Central Middlesex Hospital, our thanks for the arrangement of this symposium; both for the medical effort that has gone into devising the programme and contributing so many of the papers to it from that hospital and for the administrative and catering side who have looked after us so nicely. I am sure you would wish this to be recorded.

Our thanks also to Boehringer Ingelheim Ltd who financed the symposium and for all their help, without which this meeting would not have been possible. 